OPEN ACCESS

Edited by:

Nikolaos Papadopoulos,

University of Thessaly, Greece

Reviewed by:

Ahmad Pervez,

Radhey Hari Govt. Post Graduate

College, India

Jun-Ce Tian,

Zhejiang Academy of Agricultural

Sciences, China

Xiao-Yue Hong,

Nanjing Agricultural University, China

${ }^{*}$ Correspondence:

Hui Dong

biocontrol@163.com

Li-Sheng Zhang

zhangleesheng@163.com

tThese authors have contributed equally to this work and share first authorship

Specialty section: This article was submitted to

Population, Community, and Ecosystem Dynamics,

a section of the journal

Frontiers in Ecology and Evolution

Received: 25 June 2021 Accepted: 28 September 2021

Published: 18 October 2021

Citation:

Zhou J-C, Zhao Q, Liu S-M,

Shang $D$, Zhao X, Huo L-X, Dong H

and Zhang L-S (2021) Effects

of Thelytokous

Parthenogenesis-Inducing Wolbachia

on the Fitness of Trichogramma dendrolimi Matsumura (Hymenoptera:

Trichogrammatidae)

in Superparasitised

and Single-Parasitised Hosts.

Front. Ecol. Evol. 9:730664. doi: 10.3389/fevo.2021.730664

\section{Effects of Thelytokous}

Parthenogenesis-Inducing

Wolbachia on the Fitness of

Trichogramma dendrolimi

Matsumura (Hymenoptera:

Trichogrammatidae) in

Superparasitised and

Single-Parasitised Hosts

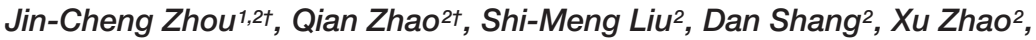 \\ Liang-Xiao Huo ${ }^{2}$, Hui Dong ${ }^{2 *}$ and Li-Sheng Zhang ${ }^{1 *}$ \\ ${ }^{1}$ Institute of Plant Protection, Chinese Academy of Agricultural Sciences, Beijing, China, ${ }^{2}$ College of Plant Protection, \\ Shenyang Agricultural University, Shenyang, China
}

Thelytokous Wolbachia-infected Trichogramma species have long been considered as biological control agents against lepidopteran pests in agriculture and forestry. Wolbachia has been suggested to increase the probability of the superparasitism of Trichogramma, but the fate of infected offspring in the superparasitised host is still unknown. The present study aimed to evaluate the fitness of thelytokous Wolbachiainfected (TDW) and bisexual Wolbachia-free (TD) Trichogramma dendrolimi Matsumura (Hymenoptera: Trichogrammatidae) lines in superparasitised or single-parasitised hosts. The results showed that irrespective of whether Trichogramma wasps were developed from superparasitised or single-parasitised hosts, the TDW line was characterized by reduced fitness, including lower fecundity, shorter longevity, and smaller body size of F1 offspring, and lower emergence rate of F2 offspring than the TD line. This was not true for the survival rate and developmental time of F1 offspring. Additionally, the fitness parameters of $T$. dendrolimi that developed from superparasitised hosts were lower compared with that of $T$. dendrolimi that developed from single-parasitised hosts. Interestingly, Wolbachia-infected females had higher dispersal capacity than bisexual females when they developed from superparasitised hosts. The results indicated that Wolbachia negatively affects fitness of $T$. dendrolimi, but enhance dispersal capacity of T. dendrolimi females in superparasitism condition. Further studies need to be carried out to select the best line that will allow Wolbachia and their host Trichogramma to be better adapted to one another.

Keywords: Wolbachia, Trichogramma dendrolimi, superparasitism, biological control, thelytokous parthenogenesis, intraspecific competition 


\section{INTRODUCTION}

The egg parasitoids Trichogramma spp. have been widely used worldwide to control lepidopteran pests in agriculture and forestry (Li, 1994; Smith, 1996; Wang et al., 2019; Zhou et al., 2019a,b; Zang et al., 2020). In general, the sex determination of Trichogramma wasps is haplodiploidy, as haploid males develop from unfertilized eggs and diploid females develop from fertilized eggs (Cook, 1993; Werren et al., 2008). However, certain strains of Trichogramma spp. only produce females, even without fertilization, in a process known as thelytoky. Thelytoky caused by parthenogenesis-inducing (PI) Wolbachia has been found in at least 15 Trichogramma species (Vavre et al., 2004; Zhang, 2009; Ma and Schwander, 2017).

Thelytokous Trichogramma has advantages in biological control programs including easier colonization without mating and less costly to rear en masse (Stouthamer, 1993; Zhou et al., 2019b, 2020). Rahimi-Kaldeh et al. (2017) found that Wolbachia infection increases fecundity of thelytokous Trichogramma brassicae Bezdenko. Vavre et al. (1999) also reported the presence of the A subdivision of Wolbachia increases fecundity of Trichogramma bourarachae Pintureau and Babault. However, others showed Wolbachia has negative effects on host fitness in most occasions, including lower emergence rate, shorter longevity, smaller body size, and lower fecundity, when compared to their uninfected counterparts (Stouthamer and Luck, 1993; Hohmann et al., 2001; Tagami et al., 2001; Miura and Tagami, 2004; Russell and Stouthamer, 2011; Zhou et al., 2020). Previous studies also found that Wolbachia is the factor that causes the occurrence of intersex (Bowen and Stern, 1966; Beserra et al., 2003; Tulgetske and Stouthamer, 2012; Ning et al., 2019). In these cases, although thelytokous Trichogramma have many advantages in biological control programs, the Wolbachia infection may have potential negative consequences on the production of thelytokous Trichogramma.

Nevertheless, our previous studies and others indicated that infected Trichogramma females show a higher probability of superparasitism, which parasitoid females lay a second clutch of eggs on a host that has been parasitised by the same species (Harvey et al., 2013; Farahani et al., 2015; Huang et al., 2017a; Liu et al., 2018; Zhou et al., 2019b). According to Lack's hypothesis as applied to gregarious parasitoids by Lack (1947) and Charnov and Skinner (1984), parasitoid females always allocate an optimal clutch size to a host to maximize offspring fitness. In superparasitised hosts, parasitoid offspring compete with each other for limited resources, leading to reduced individual fitness and increased mortality (Devescovi et al., 2017; Tunca et al., 2017; Duval et al., 2018). Thus, superparasitism had long been viewed as a maladaptive mistake of parasitoids (van Dijken and Waage, 1987; van Alphen and Visser, 1990). It is worth noting that some pathogens or symbionts can be horizontally transmitted among parasitoids when superparasitism occurs (Martinez et al., 2012; Parratt et al., 2016). Wolbachia has been found to transmit horizontally from infected to uninfected individuals as the offspring share a superparasitised host (Schilthuizen and Stouthamer, 1997; Huigens et al., 2004a; Zhang, 2009).
Some authors argue that a genomic conflict may exist between the PI Wolbachia and their host's genome, because the nuclear genes favor a population with at least some males, while PI Wolbachia favor a $100 \%$ female population (Stouthamer, 1997). In such situations, an "arms race" ensue between the Wolbachia, which try to enhance their transmission, and host nuclear genes, which try to suppress Wolbachia and their effects (Stouthamer, 1997). Consequently, a higher fitness cost is expected in infected individuals (Huigens et al., 2004b). However, Herre (1993) hypothesized that Wolbachia and the host may be better adapted to one another due to their common evolutionary fate, as the transmission of Wolbachia is largely vertical. In other words, Wolbachia quickly spreads in the host population as the host produces more offspring. Considering these two opposite hypotheses, an important question that should be tested arises: is the effect of Wolbachia on the fitness of Trichogramma offspring positive or negative in superparasitised hosts? Although previous studies have shown that Trichogramma infected by Wolbachia have higher probability for superparasitism (Huigens et al., 2004b; Farahani et al., 2015; Zhou et al., 2019b, 2020), the fate of Trichogramma offspring in the superparasitised host is still unknown.

Trichogramma dendrolimi Matsumura has been described as an effective biological control agent against many lepidopteran pest species, including Ostrinia furnacalis (Guenée) (Wang et al., 2014; Zhang et al., 2018; Zhou et al., 2019a), Mythimna separata Walker (Huang et al., 2017b; Du et al., 2018), and Mamestra brassicae (Linnaeus) (Takada et al., 2001). The adults of Trichogramma spp. can deposit several to hundreds of eggs on a relatively large lepidopteran egg, such as those of Antheraea pernyi Guérin-Méneville, Samia cynthia ricini Donovan, Helicoverpa armigera (Hübner), and M. brassicae (Takada et al., 2001; Wang et al., 2015, 2020; Iqbal et al., 2019, 2020). However, on small eggs such as those of Corcyra cephalonica (Stainton), the females of Trichogramma spp. often deposit only one egg by a single oviposition event (Li et al., 2008; Wang et al., 2015, 2019; Du et al., 2018). Owing to the easier and more exact determination of the superparasitism of host eggs, the eggs of C. cephalonica were used as the host eggs in this study.

To determine whether the effect of Wolbachia on the fitness of $T$. dendrolimi offspring is positive or negative in singleparasitised or superparasitised hosts, we tested the survival rate, body size, and developmental time of F1 offspring; fecundity, adult longevity, and dispersal capacity of F1 female offspring; and emergence rate of F2 offspring of a thelytokous Wolbachiainfected line (TDW) and a bisexual Wolbachia-uninfected line (TD) of T. dendrolimi in superparasitised or single-parasitised hosts. The single-parasitised host eggs were determined as one offspring being allocated to a C. cephalonica egg. The superparasitised host eggs were determined as two offspring being allocated to a C. cephalonica egg. As the effects of Wolbachia on the fitness of Trichogramma have rarely been examined in superparasitism condition, the results bridge some gaps in the interaction of Wolbachia and host Trichogramma, and 
provide the reference for the application of Wolbachia-infected thelytokous Trichogramma.

\section{MATERIALS AND METHODS}

\section{Insects}

The insects used in this study, including the TD and TDW of T. dendrolimi and their host C. cephalonica, were maintained in the Pest Biological Control Laboratory, Shenyang Agricultural University. All insects were reared at $25 \pm 1^{\circ} \mathrm{C}, 70 \pm 5 \%$ RH and a L16:D8 photoperiod. Both T. dendrolimi lines were originally obtained from the same bisexual isofemale line. The TDW line was first obtained by artificially transferring Wolbachia derived from infected females of Trichogramma embryophagum Hartig into developed pupae of an TD female by microinjection (Zhang, 2009). Thereafter, the females of the TDW line produced offspring that were nearly $100 \%$ female-biased even without mating. The infection of $T$. dendrolimi individuals by Wolbachia was detected and determined by specific primers (81F: 5'-TGGTCCAATAAGTGATGAAGAAAC- $3^{\prime}$ and 691R: $5^{\prime}$-AAAAATTAAACGCTACTCCA-3') for the $w s p$ gene of PI Wolbachia (Braig et al., 1998; Liu et al., 2018). The host, C. cephalonica, was reared on a semi-artificial diet (Yang et al., 1990). The C. cephalonica eggs were collected in groups of ca. 300 and then glued onto a $10 \mathrm{~mm} \times 40 \mathrm{~mm}$ card using Arabic gum solution (Arabic gum powder:water $=1: 6$ ). To prevent the hatch of $C$. cephalonica larvae, the host eggs were then killed by UVirradiation for $30 \mathrm{~min}$. Both $T$. dendrolimi lines were reared on C. cephalonica eggs by generations in the laboratory.

The active host eggs (1-day-old, without UV-irradiation) were collected in groups of 30 and glued on a white card $(10 \mathrm{~mm} \times 10 \mathrm{~mm})$ using the Arabic gum solution. The egg cards were used in this experiment.

\section{Experimental Procedure}

The egg card containing 30 glued host eggs was transferred into a small Durham glass tube $(8 \mathrm{~mm}$ diameter, $10 \mathrm{~mm}$ length, stopped with cotton balls). Thereafter, a group of $10 \mathrm{TD}$ or TDW wasps were introduced into the tube. The oviposition behaviors were observed under an anatomical lens. A single egg from the female parasitoid was successfully deposited into the host egg when a single oviposition behavior occurred with a time of fluctuating abdominal movement (Guo, 1993). The egg locations on the egg card were marked by a surgical skin marking pen $(0.5 \mathrm{~mm}$ tips, T3023; Tondaus, Dongguan, China) quickly as the oviposition behavior occurred. Ten egg cards were supplied to TD or TDW wasps for $30 \mathrm{~min}$, after which the wasps were removed. The host eggs were then reared until the eggs blackened, which occurs during the Trichogramma prepupal stages (Flanders, 1937). The blackened host eggs were cut off and transferred singly into a new Durham glass tube for emergence. Thereafter, the host egg was reared until the wasp(s) either emerged or not.

After wasp emergence, the blackened host eggs were dissected to determine the existence of a dead body of a Trichogramma offspring. The survival rate of F1 offspring was calculated by the number of wasps that emerged and the total number of offspring deposited. The single-parasitised host eggs were determined as one offspring being allocated to a C. cephalonica egg. The superparasitised host eggs were determined as two offspring being allocated to a C. cephalonica egg. Every unmated female wasp was supplied with a host egg card with approximately 300 eggs for parasitization and replaced daily. The wasps were fed with $10 \%$ honey solution via a cotton thread daily. Female lifespan and fecundity were recorded daily. The body size of the females was measured as the length of the left hind tibia.

Thirty TD or TDW females that emerged from superparasitised hosts or single-parasitised hosts, were randomly selected to test their aerial dispersal capacity by recording the flying distance according to the method of Zboralski et al. (2016). A single female was introduced into a $100 \mu \mathrm{L}$ pipette tip (50 mm height, and the wide mouth side stopped with cotton). The tip was erected in the center of an A2 paper $(594 \mathrm{~mm} \times 420 \mathrm{~mm})$ as the diving tower and the tip of the tower was coated with Vaseline to prevent the female from walking along the tip. The females had to fly from the tower and their landing positions were marked by the position of the female glued on the paper coated with vaseline. The flying distance of the female was recorded.

\section{Statistical Analysis}

Two factors were considered in this study: the parasitism type (superparasitised host eggs or single-parasitised host eggs) and the T. dendrolimi line (TD and TDW). The binary logistic regression model was used to estimate the survival rate of F1 offspring and the emergence of F2 offspring as influenced by the parasitism type and the T. dendrolimi line (Walker and Duncan, 1967). The log-linear model was used to estimate the effects of the $T$. dendrolimi line and the parasitism type on the fecundity and developmental time of $T$. dendrolimi (Berk and MacDonald, 2008). A generalized linear model with Gaussian distribution was applied to analyze the body size and flying distance as influenced by the parasitism type and the $T$. dendrolimi line.

Cox's proportional hazard model (hereafter "Cox model") was applied to quantify the adult longevity of F1 female offspring by the hazard rate, which can be interpreted biologically as the death risk at different age. The Cox model are well suited to timeto-event data (e.g., longevity of organisms), which are seldom normally distributed and cannot be made to fit the assumption of linear models with transformations. The hazard death rate at wasp's age $t$ is given by:

$$
h(t)=h_{0}(t) \exp \left\{\sum_{i=1}^{n} \beta_{i} z_{i}\right\}
$$

Where $h_{0}(t)$ is the baseline hazard function of adult death depending only on the age when all covariates $Z_{i}$ are set to zero, and $\beta_{i}$ is the regression coefficient that give the relative contribution of the $\mathrm{n}$ covariates $Z_{i}(t)$. If hazard ratio of adult death, expressed by $\exp \left\{\Sigma \beta_{i} Z_{i}\right\}$, is reduced, resulting in an increase of the adult longevity. The instantaneous death risk describe the increasing rate of mortality increased with the age. The Kaplan-Meier plot was applied to describe the curve of cumulative hazard of adult death increased with the age (Cox, 1972; Sheng et al., 2014). 
All analyses were carried out in $\mathrm{R}$ ver. 4.0.2 (R Core Team, 2020).

\section{RESULTS}

The survival rate of $\mathrm{F} 1$ offspring was not affected by the parasitism type $\left(\chi^{2}=2.19, d f=1, P=0.14\right)$, the $T$. dendrolimi line $\left(\chi^{2}=3.68, d f=1, P=0.055\right)$, or their interaction $\left(\chi^{2}=0.073\right.$, $d f=1, P=0.79$ ) (Figure 1).

The body size of F1 female offspring was significantly affected by the parasitism type $\left(\chi^{2}=205.59, d f=1, P<0.001\right)$ and the T. dendrolimi line $\left(\chi^{2}=7.08, d f=1, P=0.0078\right)$, but it was not affected by their interaction $\left(\chi^{2}=0.39\right.$, $\left.d f=1, P=0.53\right)$. The body size of the females that emerged from superparasitised hosts (TD: $120.35 \pm 2.29 \mu \mathrm{m}$; TDW: $115.76 \pm 2.02 \mu \mathrm{m}$ ) was significantly smaller than that of those that emerged from singleparasitised hosts (TD: $154.03 \pm 2.42 \mu \mathrm{m}, z=14.98, P<0.001$; TDW: $146.64 \pm 2.26 \mu \mathrm{m}, z=14.34, P<0.001)$. The body size of TD females was significantly higher $(z=2.66, P=0.0078)$ than that of TDW females (Figure 2-S1).

Fecundity of F1 female offspring was significantly affected by the parasitism type $\left(\chi^{2}=167.56, d f=1, P<0.001\right)$ or the $T$. dendrolimi line $\left(\chi^{2}=65.86, d f=1, P<0.001\right)$. Regardless of the $T$. dendrolimi line, the fecundity of the females that emerged from superparasitised hosts (TD: $71.29 \pm 4.27$; TDW: $48.44 \pm 2.13$ ) was significantly lower than that of those that emerged from single-parasitised hosts (TD: $142.90 \pm 7.55$, $z=3.64, P<0.001$; TDW: $92.37 \pm 4.39, z=2.70, P=0.0069)$. The fecundity of the TD females was significantly higher than that of the TDW females in superparasitised $(z=4.50, P<0.001)$ and single-parasitised $(z=6.68, P<0.001)$ hosts (Figure 2-S2).

The developmental time of F1 offspring was not affected by the parasitism type $\left(\chi^{2}=0.083, d f=1, P=0.77\right)$, the T. dendrolimi line $\left(\chi^{2}=2.99, d f=1, P=0.084\right)$, or their interaction ( $\left.\chi^{2}=0.0010, d f=1, P=0.99\right)$ (Figure 2-S3).

The emergence rate of F2 offspring was significantly affected by the interaction of the parasitism type and the $T$. dendrolimi line $\left(\chi^{2}=48.57, d f=1, P<0.001\right)$. The emergence rate of TDW offspring that emerged from superparasitised hosts $(61.78 \pm 2.12 \%)$ was significantly lower than that of those that emerged from single-parasitised hosts $(85.38 \pm 1.28 \% ; z=8.38$, $P<0.001)$, but the difference was non-significant in TD offspring (superparasitised host: $70.20 \pm 2.13 \%$; single-parasitised host: $70.41 \pm 2.13 \% ; \mathrm{z}=0.41, P=0.68)$. The emergence of TDW offspring was significantly higher than that of TD offspring $(z=7.22, P<0.001)$ in single-parasitised hosts, but was significantly lower than that of TD offspring $(z=2.65, P=0.0082)$ in superparasitised hosts (Figure 2-S4).

The adult longevity of F1 female offspring was significantly affected by the parasitism type $\left(\chi^{2}=18.37, d f=1, P<0.001\right)$ or the $T$. dendrolimi line $\left(\chi^{2}=4.66, d f=1, P=0.031\right)$, but it was not influenced by their interaction $\left(\chi^{2}=0.71, d f=1, P=0.40\right)$. Regardless of the T. dendrolimi line, the adult longevity of females that emerged from superparasitised hosts [instantaneous death risk: $1.37 \pm 0.22$ (TD), $1.77 \pm 0.30$ (TDW)] was significantly shorter than that of those that emerged from single-parasitised hosts (TD: $0.48 \pm 0.087, z=3.81, P<0.001$; TDW: $0.85 \pm 0.14$, $z=3.52, P<0.001)$. The adult longevity of TD females was significantly higher $(z=2.12, P=0.035)$ than that of TDW females (Figure 3).

The flying distance of F1 female offspring was significantly affected by the interaction of the parasitism type and the T. dendrolimi line $\left(\chi^{2}=15.42, d f=1, P<0.001\right)$, but it was not affected by the parasitism type $\left(\chi^{2}=3.43, d f=1\right.$, $P=0.064)$ or the $T$. dendrolimi line $\left(\chi^{2}=2.09, d f=1, P=0.15\right)$. The flying distance of TDW females in superparasitised hosts $(32.21 \pm 2.81 \mathrm{~mm})$ was significantly higher than that in singleparasitised hosts $(19.28 \pm 1.28 \mathrm{~mm} z=4.01, P<0.001)$, but the difference was non-significant in TD offspring (superparasitised host: $19.56 \pm 2.64 \mathrm{~mm}$; single-parasitised host: $25.53 \pm 2.56 \mathrm{~mm}$; $z=1.67, P=0.094)$. The difference in the flying distance between TD and TDW females was non-significant in superparasitised hosts $(z=1.24, P=0.20)$ or single-parasitised $(z=1.41, P=0.16)$ hosts (Figure 4).

\section{DISCUSSION}

Our results showed that the survival rate of F1 offspring was not affected by the parasitism type or the T. dendrolimi line. However, the fitness parameters including body size, adult longevity, and fecundity of $T$. dendrolimi females that developed from superparasitised hosts were reduced compared with those of $T$. dendrolimi females developed from single-parasitised hosts, regardless of the $T$. dendrolimi line.

Generally, the outcome of intrinsic competition depends on the host usage strategies of the parasitoids (Harvey et al., 2013). Once the hosts are superparasitised, parasitoid offspring compete for the host resources by scramble competition for the acquisition of shared host nutrition, or by contest competition for monopolization of host resource through excluding competitors. Larvae of solitary parasitoid species often destroy their competitors and gregarious parasitoid larvae often share the host resources with other individuals in a superparasitised host. T. dendrolimi can be considered a facultative gregarious species (Martel and Boivin, 2010). These tiny wasps often deposit only one egg on a small host egg, such as that of C. cephalonica, but they can also deposit a clutch of several to hundreds of eggs on a large host egg, such as those of $M$. separata, M. brassicae, and A. pernyi (Kong et al., 1988; Takada et al., 2001; Wang et al., 2015). However, the larvae of Trichogramma carverae Oatman and Pinto have been observed to siphon and kill their siblings (Heslin and Merritt, 2005). So far, T. dendrolimi larvae have not been observed to initiate aggressive attacks. If the larva shows a form of scramble competition, most offspring would emerge, but with reduced fitness. Our previous study and others revealed that infected parasitoids have a higher probability of parasitizing host eggs that had been previously parasitised (Farahani et al., 2015; Liu et al., 2018). In superparasitised hosts, Wolbachia gains the opportunity for horizontal transmission from infected Trichogramma individuals to uninfected Trichogramma individuals (Huigens et al., 2004a; 


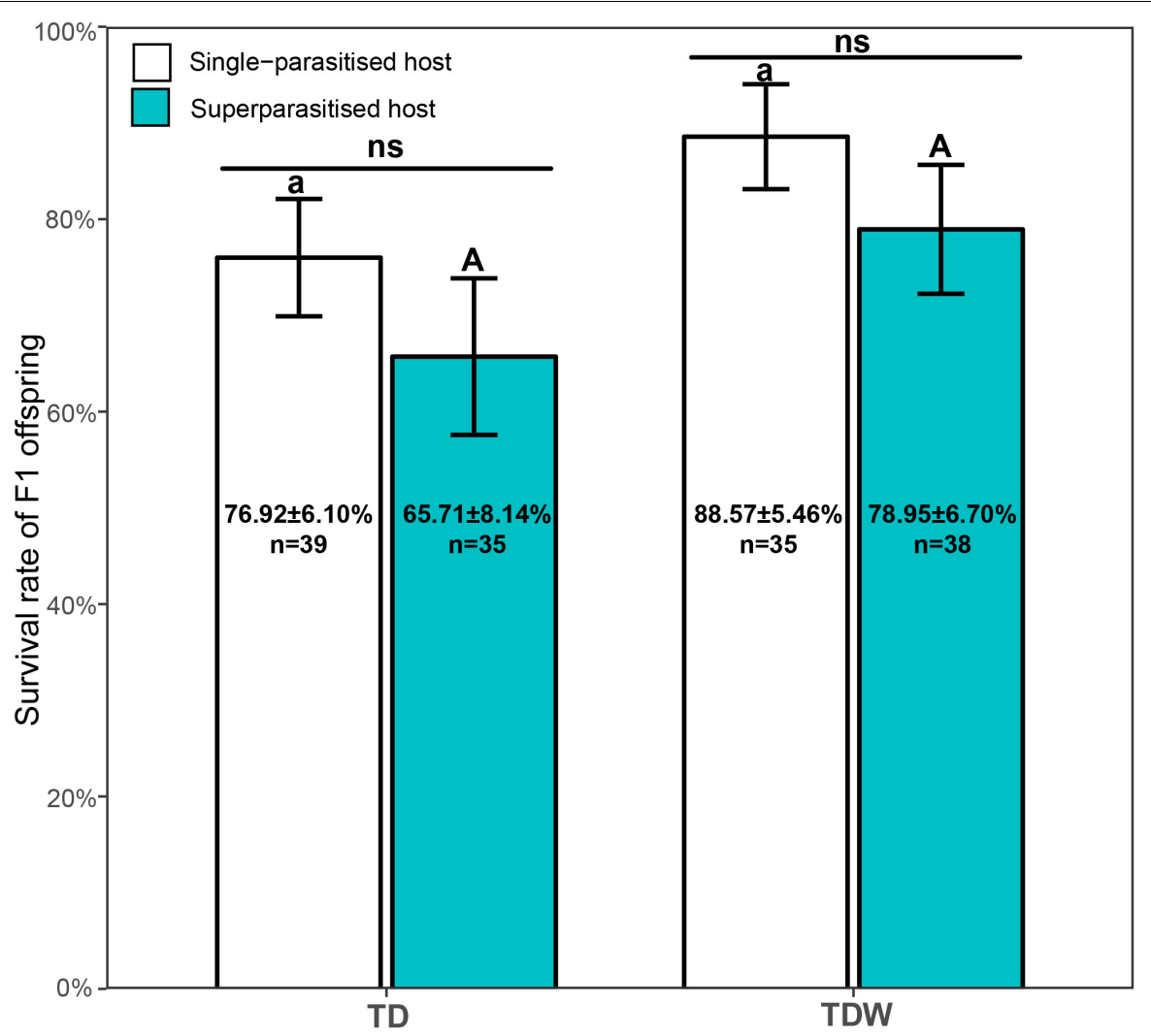

FIGURE 1 | Survival rate of TDW or TD F1 offspring in superparasitised (cyan bars) or single-parasitised (white bars) hosts. Bars indicate Means. Error bars indicate the interval of Mean \pm Standard Error. The same uppercase letters indicate non-significant difference between TD $(n=35)$ and TDW $(n=38)$ in superparasitised hosts. The same lowercase letters indicate non-significant difference between TD $(n=39)$ and TDW $(n=35)$ in single-parasitised hosts. "ns" indicates non-significant difference between superparasitised hosts and single-parasitised hosts. Texts labeled on the bars indicate sample size and values of Mean \pm Standard Error.
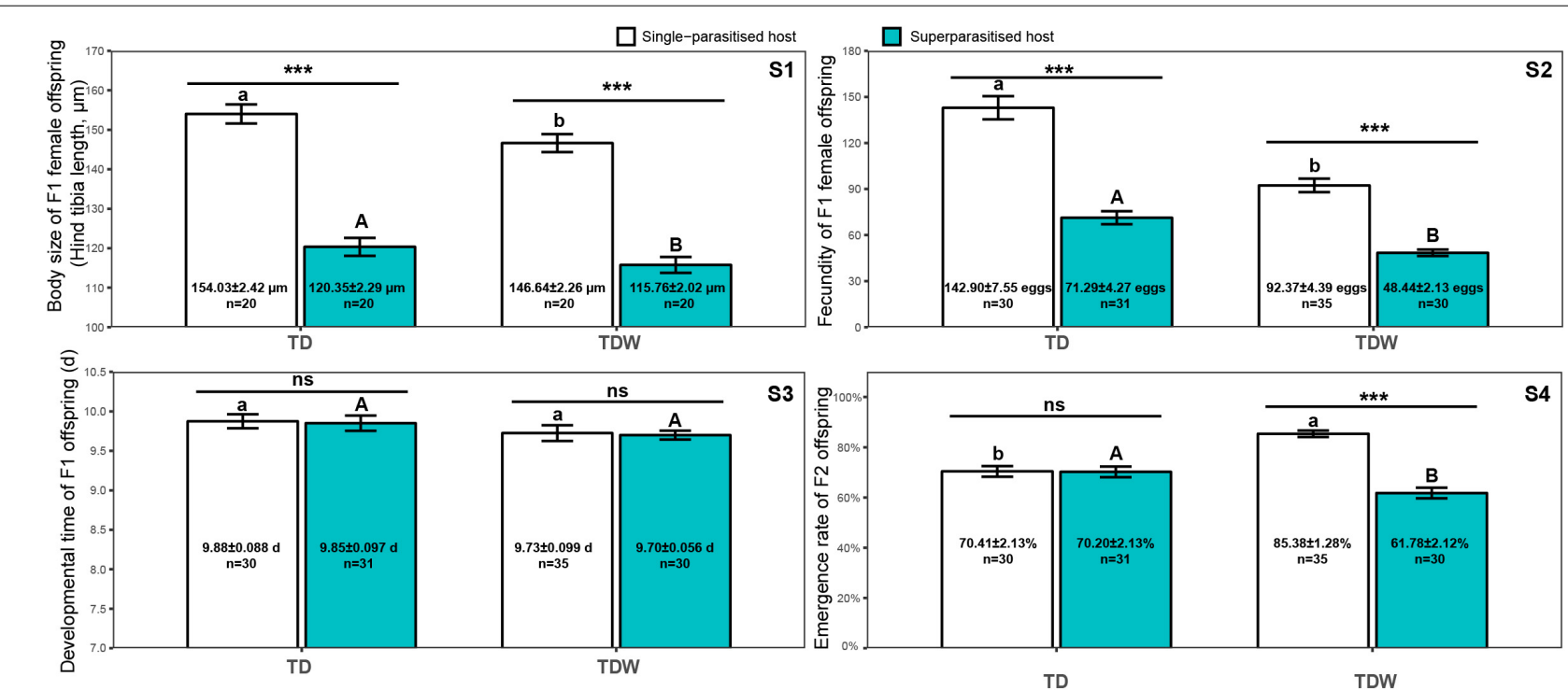

FIGURE 2 | Body size of F1 female offspring (S1), fecundity of F1 female offspring (S2), developmental time of F1 offspring (S3), and emergence rate of F2 offspring (S4) of TDW or TD line in superparasitised (cyan bars) or single-parasitised (white bars) hosts. Bars indicate Means. Error bars indicate the interval of Mean \pm Standard Error. The different uppercase letters indicate significant difference between TD and TDW in superparasitised hosts. The different lowercase letters

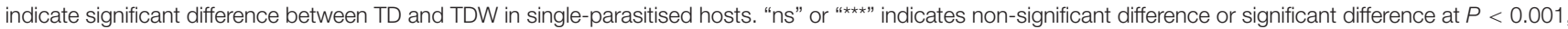
respectively, between superparasitised hosts and single-parasitised hosts. Texts labeled on the bars indicate sample size and values of Mean \pm Standard Error. 

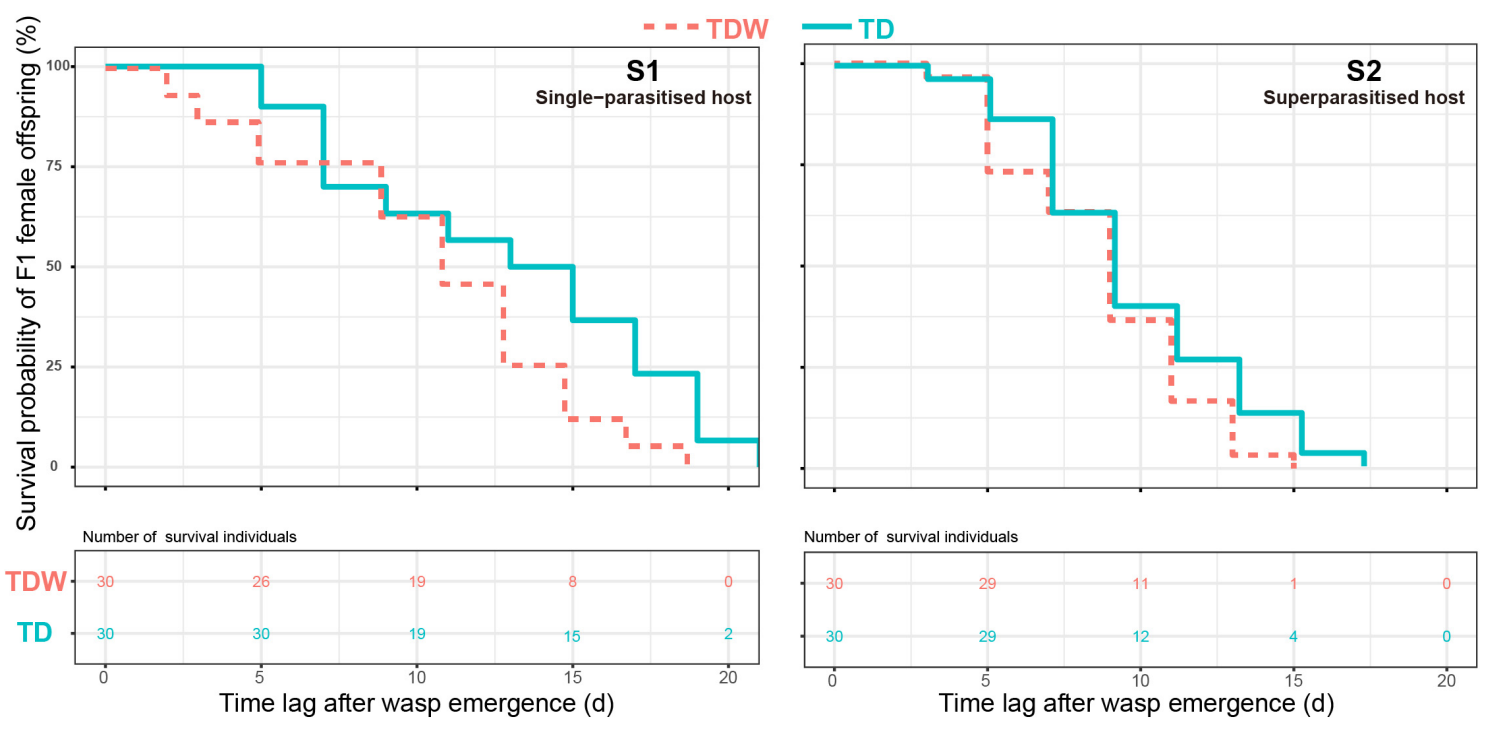

FIGURE 3 | Kaplan-Meier curve of adult survivorship and survival number of TDW (red) or TD (cyan) F1 female offspring in single-parasitised (S1) or superparasitised (S2) hosts with the time extended.

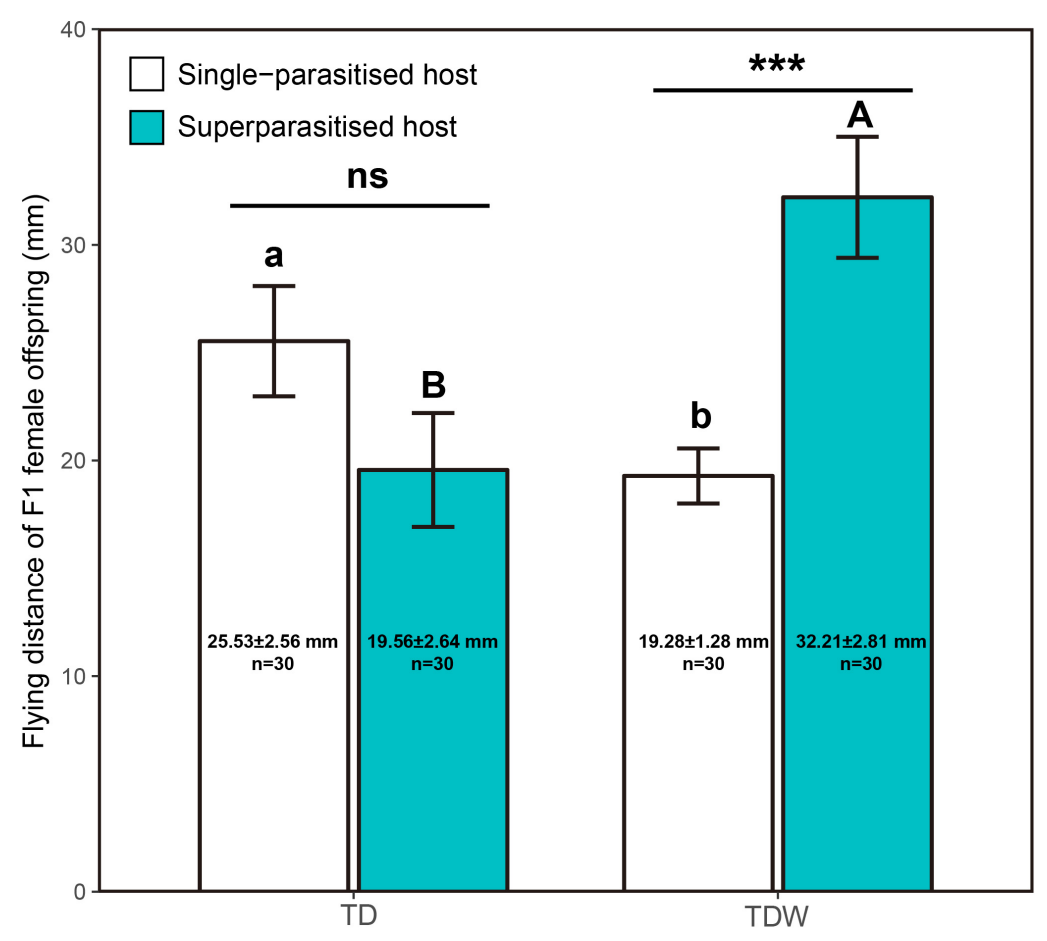

FIGURE 4 | Flying distance of TDW or TD F1 female offspring developed from superparasitised or single-parasitised hosts. Bars indicate Means. Error bars indicate the interval of Mean \pm Standard Error. The different uppercase letters indicate significant difference between TD $(n=30)$ and TDW $(n=30)$ in superparasitised hosts.

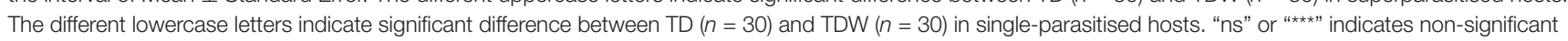
difference or significant difference at $P<0.001$, respectively, between superparasitised hosts and single-parasitised hosts. Texts labeled on the bars indicate sample size and values of Mean \pm Standard Error.

Farahani et al., 2015; Liu et al., 2018). Thus, superparasitism may have a positive effect on the spread of Wolbachia.

Our results also showed that the infected line of $T$. dendrolimi had reduced fitness, including lower fecundity and a shorter longevity, than the uninfected $T$. dendrolimi line, regardless if it was developed in superparasitised or single-parasitised hosts. However, the survival rate of F1 offspring did not vary among parasitism types or $T$. dendrolimi lines. The results 
support the genomic conflict hypothesis that exists between the PI-Wolbachia and their host's genome. Superparasitism does not seem to be an adaption of $T$. dendrolimi wasps to PIWolbachia.

Similar to our results, other studies also reported that the infected Trichogramma offspring exhibit greater mortality, shorter longevity, and smaller body size (Tagami et al., 2001; Huigens et al., 2004b). PI-Wolbachia can convert the haploid eggs of Trichogramma into diploid embryos through an aborted first mitotic division. This mechanism is called gamete duplication. Consequently, homozygous individuals develop as females. In contrast, the nuclear genes of the host favor a sex ratio with at least some males developed from haploid eggs and try to suppress Wolbachia and their effects. This arms race between the nuclear genes of hosts and PI Wolbachia may lead to a higher fitness cost in infected individuals (Stouthamer et al., 2010). First, the conflicts between Wolbachia and host Trichogramma may lead to delayed hatching in the early mitotic stage of Trichogramma embryo. Hohmann and Luck (2000) reported that the infected offspring of Trichogramma kaykai Pinto and Stouthamer took approximately half a day longer than uninfected offspring to hatch. Tagami et al. (2001) found that most embryos of uninfected Trichogramma could develop to the cellular blastoderm stage $6 \mathrm{~h}$ after oviposition, while approximately $35 \%$ of embryos of infected Trichogramma still remained at the mitotic stage even $48 \mathrm{~h}$ after oviposition. Owing to the delayed hatching, the Trichogramma offspring may be unable to obtain sufficient nutrition from the host eggs especially in superparasitism conditions. A second factor suspected to affect the fitness of Wolbachia-infected Trichogramma larvae, is their requirement for more nutrients when compared to that of uninfected counterparts (Huigens et al., 2004b). During the mitotic proliferation of host organisms, Wolbachia divides rapidly and rely on nutrients and energy sources provided by the host (Landmann et al., 2010; Grote et al., 2017). Rahimi Kaldeh et al. (2017) implied that the presence of Wolbachia may cause energy reduction when facing stresses. Although potential quality risks exist in PI Wolbachia-infected Trichogramma wasps, the PI Wolbachia-infected thelytokous Trichogramma line will allow a predictable performance in fields and could be used as a population to help maintain a typical genotype and traits without change. Genetic improvement methods should be encouraged to select the best line in the future. For example, Ebrahimi et al. (2019) tried to create a set of completely homozygous Wolbachia-infected recombinant lines by hybridizing Wolbachia-infected Trichogramma wasps and bisexual wasps.

Though the infected Trichogramma offspring is less competitive relative to uninfected offspring when competing in superparasitised hosts, we found Trichogramma offspring benefit for survivorship from Wolbachia in single-parasitised hosts. Our previous study also observed a higher emergence of Wolbachia-infected offspring than that of uninfected offspring when the wasps emerged from A. pernyi eggs (Zhou et al., 2020). One potential explanation is that Wolbachia protect hosts against a broad range of pathogens by induction of host innate immune responses or competing with pathogens for nutrients
(Brownlie and Johnson, 2009; Zhang et al., 2020). Some studies doubted that the abortion of Trichogramma offspring may be caused by the vertical transmitted pathogens like Nosema spp. and pathogenic bacteria in host eggs ( $\mathrm{Pu}, 1983$; Ruan et al., 2000; Qin, 2015; Zhao et al., 2019). Therefore, further investigations need to be carried out to bridge the gaps in knowledge pertaining to the pathogenicity of the pathogens in Trichogramma. Another explanation is that Wolbachia has evolved nutritional mutualism for the survival of host organisms (Braquart-Varnier et al., 2015). For example, Wolbachia is the supplier of B vitamins for their hosts (Hosokawa et al., 2010; Ju et al., 2020). Although Wolbachia protect immature Trichogramma offspring against death, Wolbachia also taxes resources of infected Trichogramma offspring, necessitating a longer developmental time and requirement for more nutrients (Huigens et al., 2004b). Thus the infected Trichogramma offspring is less competitive for limited resources in intra-specific competition.

Interestingly, our results showed that Wolbachia-infected females had a higher dispersal capacity than bisexual females when they developed from superparasitised hosts. Similar results were also found in Laodelphax striatellus (Fallén) (Sun et al., 2015), Coccotrypes dactyliperda Fabricius (Tremmel et al., 2020), and Aedes aegypti (Linnaeus) (Evans et al., 2009). Caragata et al. (2011) found that Wolbachia infection increases the recapture rate of field-released Drosophila melanogaster Meigen. Hoffmann et al. (2007) revealed that Wolbachia infection results in size differences in flies and, consequently, affects their dispersal distances. Nevertheless, infecting nervous tissues with Wolbachia could also influence the locomotor activities of insects (Strunov et al., 2013). While in this study we showed that the increased dispersal capacity of infected wasps might be driven by superparasitism, the mechanism behind this phenomenon was not explained. Future studies should be encouraged to examine the dispersal behaviors and motivation of infected females under superparasitism conditions.

Although Wolbachia and the host will be better adapted to one another as Wolbachia quickly spreads in the host population when the host produces more offspring, Wolbachia-infected T. dendrolimi wasps could not benefit from superparasitism according to our results. However, the experiments were conducted in laboratory conditions. The Wolbachia-infected and uninfected lines have been separately reared on intermediate hosts for over 40 generations. This makes it a little challenging to be confident that the effects were directly attributable to Wolbachia. It is critical to clarify the effects of Wolbachia on the intraspecific competition of Trichogramma offspring in field conditions. In biological control programs, genetic improvement methods should be encouraged to select the best line that will allow Wolbachia and the host to be better adapted to one another in the future.

\section{DATA AVAILABILITY STATEMENT}

The original contributions presented in the study are included in the article/Supplementary Material, further inquiries can be directed to the corresponding author/s. 


\section{AUTHOR CONTRIBUTIONS}

L-SZ, J-CZ, and HD: conceptualization and funding acquisition. QZ, S-ML, L-XH, XZ, DS, J-CZ, and HD: data curation. J-CZ and QZ: original draft writing. J-CZ, QZ, HD, and L-SZ: review and editing. All authors contributed to the article and approved the submitted version.

\section{FUNDING}

This research was funded by the Projects of Guizhou Tobacco Corporation (201936, 201937, and 201941), the Major Projects of China National Tobacco Corporation [110202001032 (LS-01)], the National Natural Science Foundation of China (31972339), the Agricultural Science and Technology Innovation Program (CAAS-ZDRW202108), the Natural Science Foundation of

\section{REFERENCES}

Berk, R., and MacDonald, J. (2008). Overdispersion and poisson regression. J. Quant. Criminol. 24, 269-284. doi: 10.1007/s10940-008-9048-9044

Beserra, E. B., Querino, R. B., and Parra, J. R. P. (2003). Occurrence of gynandromorphism in Trichogramma pretiosum riley (Hymenoptera: Trichogrammatidae). Neotrop. Entomol. 32, 507-509. doi: 10.1590/S1519566X2003000300021

Bowen, W. R., and Stern, V. M. (1966). Effect of temperature on the production of males and sexual mosaics in a uniparental race of Trichogramma semifumatum (Hymenoptera: Trichogrammatidae). Ann. Entomol. Soc. Am. 59, 823-834. doi: 10.1093/aesa/59.4.823

Braig, H. R., Zhou, W., Dobson, S. L., and O’Neill, S. L. (1998). Cloning and characterization of a gene encoding the major surface protein of the bacterial endosymbiont Wolbachia pipientis. J. Bacteriol. 180, 2373-2378. doi: 10.1128/ JB.180.9.2373-2378.1998

Braquart-Varnier, C., Altinli, M., Pigeault, R., Chevalier, F. D., Greve, P., Bouchon, D., et al. (2015). The mutualistic side of Wolbachia-isopod interactions: wolbachia mediated protection against pathogenic intracellular bacteria. Front. Microbiol. 6:1388. doi: 10.3389/fmicb.2015.01388

Brownlie, J. C., and Johnson, K. N. (2009). Symbiont-mediated protection in insect hosts. Trends Microbiol. 17, 348-354. doi: 10.1016/j.tim.2009.05.005

Caragata, E. P., Real, K. M., Zalucki, M. P., and McGraw, E. A. (2011). Wolbachia infection increases recapture rate of field-released Drosophila melanogaster. Symbiosis 54, 55-60. doi: 10.1007/s13199-011-0124-4

Charnov, E. L., and Skinner, S. W. (1984). Evolution of host selection and clutch size in parasitoid wasps. Florida Entomol. 67, 5-21. doi: 10.2307/3494101

Cook, J. M. (1993). Sex determination in the Hymenoptera: a review of models and evidence. Heredity 71, 421-435. doi: 10.1038/hdy.1993.157

Cox, D. R. (1972). Regression models and life-tables. J. R. Stat. Soc. 74, 187-120. doi: 10.1111/j.2517-6161.1972.tb00899.x

Devescovi, F., Bachmann, G. E., Nussenbaum, A. L., Viscarret, M. M., Cladera, J. L., and Segura, D. F. (2017). Effects of superparasitism on immature and adult stages of Diachasmimorpha longicaudata Ashmead (Hymenoptera: Braconidae) reared on Ceratitis capitata Wiedemann (Diptera: Tephritidae). Bull. Entomol. Res. 107, 756-767. doi: 10.1017/S000748531700027X

Du, W. M., Xu, J., Hou, Y. Y., Lin, Y., Zang, L. S., Yang, X. B., et al. (2018). Trichogramma parasitoids can distinguish between fertilized and unfertilized host eggs. J. Pest Sci. 91, 771-780. doi: 10.1007/s10340-017-0919-z

Duval, J., Brodeur, J., Doyon, J., and Boivin, G. (2018). Impact of superparasitism time intervals on progeny survival and fitness of an egg parasitoid. Ecol. Entomol. 43, 310-317. doi: 10.1111/een.12502

Ebrahimi, V., Ashouri, A., Rugman-Jones, P. F., Lindsey, A. R. I., Javan-Nikkhah, M., and Stouthamer, R. (2019). Using parthenogenesis-inducing Wolbachia for the selection of optimal lines of the egg parasitoid Trichogramma pretiosum for use in biocontrol. Entomol. Exp. Appl. 167, 241-251. doi: 10.1111/eea.12755
Liaoning Province (2020-BS-137), and the Fundamental Research Funds for the Universities of Liaoning Province (LR2019061).

\section{ACKNOWLEDGMENTS}

We should thank ELSEVIER Language Editing Services for improving the language.

\section{SUPPLEMENTARY MATERIAL}

The Supplementary Material for this article can be found online at: https://www.frontiersin.org/articles/10.3389/fevo.2021. 730664/full\#supplementary-material

Evans, O., Caragata, E. P., McMeniman, C. J., Woolfit, M., Green, D. C., McGraw, E. A., et al. (2009). Increased locomotor activity and metabolism of Aedes aegypti infected with a life-shortening strain of Wolbachia pipientis. J. Exp. Biol. 212, 1436-1441. doi: 10.1242/jeb.028951

Farahani, K. H., Ashouri, A., Goldansaz, S. H., Farrokhi, S., Ainouche, A., and Baaren, J. (2015). Does Wolbachia infection affect decision-making in a parasitic wasp? Entomol. Exp. Appl. 155, 102-116. doi: 10.1111/eea.12293

Flanders, S. E. (1937). Notes on the life history and anatomy of Trichogramma. Ann. Entomol. Soc. Am. 30, 304-308. doi: 10.1093/aesa/30.2.304

Grote, A., Voronin, D., Ding, T., Twaddle, A., and Ghedin, E. (2017). Defining Brugia malayi and Wolbachia symbiosis by stage-specific dual RNA-seq. PLoS Neglected Trop. Dis. 11:e0005357. doi: 10.1371/journal.pntd.0005357

Guo, M. (1993). Study of parasitizing behaviour of Trichogramma (IV)—progeny number allocation and sex allocation. Nat. Enemies Insects 15, 51-59.

Harvey, J. A., Poelman, E. H., and Tanaka, T. (2013). Intrinsic inter and intraspecific competition in parasitoid wasps. Annu. Rev. Entomol. 58, 333-351. doi: 10.1146/annurev-ento-120811-153622

Herre, E. A. (1993). Population structure and the evolution of virulence in nematode parasites of fig wasps. Science 259, 1442-1445. doi: 10.1126/science. 259.5100.1442

Heslin, L. M., and Merritt, D. J. (2005). Cannibalistic feeding of larval Trichogramma carverae parasitoids in moth eggs. Naturwissenschaften 92, 435-439. doi: 10.1007/s00114-005-0015-8

Hoffmann, A. A., Ratna, E., Sgro, C. M., Barton, M., Blacket, M., Hallas, R., et al. (2007). Antagonistic selection between adult thorax and wing size in field released Drosophila melanogaster independent of thermal conditions. J. Evol. Biol. 6, 2219-2227. doi: 10.1111/j.1420-9101.2007.01422.x

Hohmann, C. L., and Luck, R. F. (2000). Effect of temperature on the development and thermal requirements of Wolbachia-infected and antibiotically cured Trichogramma kaykai Pinto and Stouthamer (Hymenoptera: Trichogrammatidae). Anais Soc. Entomol. Do Brasil 25, 3888-3898. doi: 10.1590/s0301-80592000000300012

Hohmann, C. L., Luck, R. F., and Stouthamer, R. (2001). Effect of Wolbachia on the survival and reproduction of Trichogramma kaykai Pinto \& Stouthamer (Hymenoptera: Trichogrammatidae). Neotrop. Entomol. 30, 607-612. doi: 10. 1590/S1519-566X2001000400015

Hosokawa, T., Koga, R., Kikuchi, Y., Meng, X. Y., and Fukatsu, T. (2010). Wolbachia as a bacteriocyte-associated nutritional mutualist. Proc. Natl. Acad. Sci. U S A. 107, 769-774. doi: 10.1073/pnas.0911476107

Huang, J., Hua, H. Q., Wang, L. Y., Zhang, F., and Li, Y. X. (2017a). Number of attacks by Trichogramma dendrolimi (Hymenoptera: Trichogrammatidae) affects the successful parasitism of Ostrinia furnacalis (Lepidoptera: Crambidae) eggs. Bull. Entomol. Res. 107, 1-8. doi: 10.1017/S0007485317000335

Huang, J., Hua, H. Q., Zhang, F., and Li, Y. X. (2017b). Suitability assessment of three Trichogramma species in the control of Mythimna separata (Lepidoptera: Noctuidae). J. Appl. Entomol. 142, 131-140. doi: 10.1111/jen.12414 
Huigens, M. E., de Almeida, R. P., Boons, P. A. H., Luck, R. F., and Stouthamer, R. (2004a). Natural interspecific and intraspecific horizontal transfer of parthenogenesis-inducing Wolbachia in Trichogramma wasps. Proc. R. Soc. B-Biol. Sci. 271, 509-515. doi: 10.1098/rspb.2003.2640

Huigens, M. E., Hohmann, C. L., Luck, R. F., Gort, G., and Stouthamer, R. (2004b). Reduced competitive ability due to Wolbachia infection in the parasitoid wasp Trichogramma kaykai. Entomol. Exp. Appl. 110, 115-123. doi: 10.1111/j.00138703.2004.00126.x

Iqbal, A., Chen, Y. M., Hou, Y. Y., Zhang, L. S., Desneux, N., and Zang, L. S. (2019). Factitious host species impact on the outcome of multiparasitism between egg parasitoids. J. Pest Sci. 92, 1261-1269. doi: 10.1007/s10340-019-01 $122-8$

Iqbal, A., Hou, Y. Y., Chen, Y. M., Ali, A., Monticelli, L. S., Desneux, N., et al. (2020). Impact of Trichogramma parasitoid age on the outcome of multiparasitism in the factitious host eggs of Chinese oak silkworm. Antheraea pernyi. J. Pest Sci. 93, 1347-1357. doi: 10.1007/s10340-020-01239-1

Ju, J. F., Bing, X. L., Zhao, D. S., Guo, Y., Xi, Z. Y., Hong, X. Y., et al. (2020). Wolbachia supplement biotin and riboflavin to enhance reproduction in planthoppers. ISME J. 14, 676-687. doi: 10.1038/s41396-019-0559-9

Kong, J., Peng, H., Chen, H. Y., and Bao, J. Z. (1988). Unusual mating behaviour of Trichogramma dendrolimi (Hym. Trichogrammatidae) reared on oak silkworm eggs. Chinese J. Biol. Control 4, 50-54. doi: 10.16409/j.cnki.2095-039x.1988.02. 001

Lack, D. (1947). The significance of clutch-size. IBIS 89, 309-352. doi: 10.1111/j. 1474-919X.1947.tb04155.x

Landmann, F., Foster, J. M., Slatko, B., and Sullivan, W. (2010). Asymmetric Wolbachia segregation during early Brugia malayi embryogenesis determines its distribution in adult host tissues. PLoS Neglected Trop. Dis. 4:e758. doi: 10.1371/journal.pntd.0000758

Li, L. Y. (1994). "Worldwide use of Trichogramma for biological control on different crops: a survey," in Biological Control with Egg Parasitoids, eds E. Wajnberg and S. A. Hassan (Wallingford: CABI).

Li, Y. X., Dai, G. H., and Fu, W. J. (2008). Suitability of Corcyra cephalonica to three Trichogramma species and change of the content of free amino acids in its eggs parasitized. Acta Entomol. Sinica 51, 628-634. doi: 10.16380/j.kcxb.2008.06.012

Liu, Q. Q., Zhang, T. S., Li, C. X., Gu, J. W., Hou, J. B., and Dong, H. (2018). Decision-making in a bisexual line and a thelytokous Wolbachia-infected line of Trichogramma dendrolimi Matsumura (Hymenoptera: Trichogrammatidae) toward their hosts. Pest. Manag. Sci. 74, 1720-1727. doi: 10.1002/ps.4867

Ma, W. J., and Schwander, T. (2017). Patterns and mechanisms in instances of endosymbionts-induced parthenogenesis. J. Evol. Biol. 30, 868-888. doi: 10. 1111/jeb.13069

Martel, V., and Boivin, G. (2010). Unequal distribution of local mating opportunities in an egg parasitoid. Ecol. Entomol. 32, 393-398. doi: 10.1111/j. 1365-2311.2007.00895.x

Martinez, J., Duplouy, A., Woolfit, M., Vavre, F., O’Neill, S. L., and Varaldi, J. (2012). Influence of the virus LbFV and of Wolbachia in a host-parasitoid interaction. PLoS One 7:e35081. doi: 10.1371/journal.pone.0035081

Miura, K., and Tagami, Y. (2004). Comparison of life history characters of arrhenotokous and Wolbachia-associated thelytokous Trichogramma kaykai Pinto and Stouthamer (Hymenoptera: Trichogrammatidae). Ann. Entomol. Soc. Am. 97, 765-769.

Ning, S. F., Zhou, J. C., Liu, Q. Q., Zhao, Q., and Dong, H. (2019). Gradual, temperature-induced change of secondary sexual characteristics in Trichogramma pretiosum infected with parthenogenesis-inducing Wolbachia. PeerJ 7:e7567. doi: 10.7717/peerj.7567

Parratt, S. R., Frost, C. L., Schenkel, M. A., Rice, A., Hurst, G. D., and King, K. C. (2016). Superparasitism drives heritable symbiont epidemiology and host sex ratio in a wasp. PLoS Pathogens 12:e1005629. doi: 10.1371/journal.ppat. 1005629

Pu, Z. (1983). Studies on three potential pathogens, Staphylococcus, Rickettsialike and Microplasma-like organisms of Trichogramma spp and their causative diseases of the hosts. Acta Sci. Nat. Universitatis Sunyatseni 4, 118-122.

Qin, Y. L. (2015). Morphological and molecular characterization of Nosema pernyi, a microsporidian parasite in Antheraea pernyi. Parasitol. Res. 114, 3327-3336. doi: 10.1007/s00436-015-4558-0

R Core Team (2020). R: A Language and Environment for Statistical Computing. Vienna: R Foundation for Statistical Computing.
Rahimi Kaldeh, S., Ashouri, A., Bandani, A., and Modarres Hasani, S. A. (2017). The maternal effect of temperature on diapause induction in Wolbachiainfected and uninfected Trichogramma brassicae. Plant Pest Res. 7, 25-35. doi: 10.22124/IPRJ.2017.2437

Rahimi-Kaldeh, S., Ashouri, A., Bandani, A., and Tomioka, K. (2017). The effect of Wolbachia on diapause, fecundity, and clock gene expression in Trichogramma brassicae (Hymenoptera: Trichogrammatidae). Dev. Genes Evol. 227, 401-410. doi: 10.1007/s00427-017-0597-0

Ruan, C., Zhu, X., Meng, Z., and Su, R. (2000). Influences of Antheraea pernys diseases on eggs host of Trichogramma. J. Jilin Agricul. University 3, 22-26.

Russell, J. E., and Stouthamer, R. (2011). The genetics and evolution of obligate reproductive parasitism in Trichogramma pretiosum infected with parthenogenesis-inducing Wolbachia. Heredity 106, 58-67. doi: 10.1038/hdy. 2010.48

Schilthuizen, M., and Stouthamer, R. (1997). Horizontal transmission of parthenogenesis-inducing microbes in Trichogramma wasps. Proc. R. Soc. B-Biol. Sci. 264, 361-366. doi: 10.1098/rspb.1997.0052

Sheng, S., Feng, S., Meng, L., and Li, B. P. (2014). Departure mechanisms for host search on high density patches in the parasitoid Meteorus pulchricornis (Wesmael) (Hymenoptera: Braconidae). J. Insect. Sci. 14, 1-5. doi: 10.1093/ jisesa/ieu067

Smith, S. M. (1996). Biological control with Trichogramma: advances, successes, and potential of their use. Annu. Rev. Entomol. 41, 375-406. doi: 10.1146/ annurev.en.41.010196.002111

Stouthamer, R. (1993). The use of sexual versus asexual wasps in biological control. Entomophaga 38, 3-6. doi: 10.1007/BF02373133

Stouthamer, R. (1997). "Wolbachia-induced parthenogenesis," in Influential Passengers: Inherited Microorganisms and Arthropod Reproduction, eds S. L. O’Neill, A. A. Hoffmann, and J. H. Werren (Oxford: Oxford University Press), $102-122$.

Stouthamer, R., and Luck, R. F. (1993). Influence of microbe-associated parthenogenesis on the fecundity of Trichogramma deion and T. pretiosum. Entomol. Exp. Appl. 67, 183-192. doi: 10.1111/j.1570-7458.1993.tb01667.x

Stouthamer, R., Russell, J. E., Vavre, F., and Nunney, L. (2010). Intragenomic conflict in populations infected by parthenogenesis inducing Wolbachia ends with irreversible loss of sexual reproduction. BMC Evol. Biol. 10:229. doi: 10. 1186/1471-2148-10-229

Strunov, A., Kiseleva, E., and Gottlieb, Y. (2013). Spatial and temporal distribution of pathogenic Wolbachia strain wmel pop in Drosophila melanogaster central nervous system under different temperature conditions. J. Invertebrate Pathol. 114, 22-30. doi: 10.1016/j.jip.2013.05.001

Sun, J. T., Wang, M. M., Zhang, Y. K., Chapuis, M. P., Jiang, X. Y., Hu, et al. (2015). Evidence for high dispersal ability and mito-nuclear discordance in the small brown planthopper. Laodelphax striatellus. Sci. Rep. 5:8045.

Tagami, Y., Miura, K., and Stouthamer, R. (2001). How does infection with parthenogenesis-inducing Wolbachia reduce the fitness of Trichogramma? J. Invertebrate Pathol. 78, 267-271. doi: 10.1006/jipa.2002.5080

Takada, Y., Kawamura, S., and Tanaka, T. (2001). Host preference of Trichogramma dendrolimi (Hymenoptera :Trichogrammatidae) on its native host, Mamestra brassicae (Lepidoptera: Noctuidae) after 12 continuous generations on a factitious host. Appl. Entomol. Zool. 36, 213-218. doi: 10.1303/ aez. 2001.213

Tremmel, M., Steinitz, H., Kliot, A., Harari, A., and Lubin, Y. D. (2020). Dispersal, endosymbiont abundance and fitness-related consequences of inbreeding and outbreeding in a social beetle. Biol. J. Linnean Soc. 129, 717-727. doi: 10.1093/ biolinnean/blz204

Tulgetske, G. M., and Stouthamer, R. (2012). Characterization of intersex production in Trichogramma kaykai infected with parthenogenesis-inducing Wolbachia. Naturwissenschafen 99, 143-152. doi: 10.1007/s00114-011-0880-2

Tunca, H., Colombel, E. A., Venard, M., and Tabone, E. (2017). Incidence of superparasitism in the egg parasitoid, Ooencyrtus kuvanae howard (Hymenoptera: Encyrtidae). Biocontrol Sci. Technol. 27, 796-808. doi: 10.1080/ 09583157.2017.1342765

van Alphen, J. J. M., and Visser, M. E. (1990). Superparasitism as an adaptive strategy for insect parasitoids. Annu. Rev. Entomol. 35, 59-79. doi: 10.1146/ annurev.en.35.010190.000423

van Dijken, M. J., and Waage, J. K. (1987). Self and conspecific superparasitism by the egg parasitoid Trichogramma evanescens. Entomol. Exp. Appl. 43, 183-192. 
Vavre, F., de Jong, J. H., and Stouthamer, R. (2004). Cytogenetic mechanism and genetic consequences of thelytoky in the wasp Trichogramma cacoeciae. Heredity 93, 592-596. doi: 10.1038/sj.hdy.6800565

Vavre, F., Girin, C., and Boulétreau, M. (1999). Phylogenetic status of a fecundityenhancing Wolbachia that does not include thelytoky in Trichogramma. Insect Mol. Biol. 8, 67-67. doi: 10.1046/j.1365-2583.1999.810067.x

Walker, S. H., and Duncan, D. B. (1967). Estimation of the probability of an event as a function of several independent variables. Biometrika 54, 167-178. doi: 10.1093/biomet/54.1-2.167

Wang, L., Huang, J., Dong, X., Zhang, F., and Li, Y. X. (2015). Superparasitism and ontogeny of two Trichogramma species on Corcyra cephalonica (Stainton). Chinese J. Biol. Control 31, 481-486. doi: 10.16409/j.cnki.2095-039x.2015.04. 006

Wang, Y., Xiang, M., Hou, Y. Y., Yang, X. B., Dai, H. J., Zang, L. S., et al. (2019). Impact of egg deposition period on the timing of adult emergence in Trichogramma parasitoids. Entomol. Generalis 39, 339-346. doi: 10.1127/ entomologia/2019/0896

Wang, Y., Zou, Z. P., Hou, Y. Y., Yang, X., and Zang, L. S. (2020). Manuallyextracted unfertilized eggs of Chinese oak silkworm, Antheraea pernyi, enhance mass production of Trichogramma parasitoids. Entomologia Generalis 40, 397406. doi: 10.1127/entomologia/2020/1060

Wang, Z. Y., He, K. L., Zhang, F., Lu, X., and Babendreier, D. (2014). Mass rearing and release of Trichogramma for biological control of insect pests of corn in China. Biol. Control 68, 136-144. doi: 10.1016/j.biocontrol.2013.06.015

Werren, J. H., Baldo, L., and Clark, M. E. (2008). Wolbachia: master manipulators of invertebrate biology. Nat. Rev. Microbiol. 6, 741-751. doi: 10.1038/ nrmicro1969

Yang, C. C., Wang, J. L., and Zhang, J. (1990). Screening the diet prescription for rice moth rearing. J. Shenyang Agricultural University 21, 48-52.

Zang, L. S., Wang, S., Zhang, F., and Desneux, N. (2020). Biological control with trichogramma in china: history, present status, and perspectives. Annu. Rev. Entomol. 66, 463-484. doi: 10.1146/annurev-ento-060120-091620

Zboralski, A., Vilarelle, M., Colombel, E., Tabone, E., and Vercken, E. (2016). Density-dependent dispersal in biological control agents: a reflexion on the side-effects of mass-rearing conditions. BioControl 61, 13-22. doi: 10.1007/ s10526-015-9696-x

Zhang, D., Wang, Y., He, K., Yang, Q., and Chen, L. (2020). Wolbachia limits pathogen infections through induction of host innate immune responses. PLoS One 15:e0226736. doi: 10.1371/journal.pone.0226736

Zhang, H. Y. (2009). Wolbachia Transfection and Biological Control Capability of Trichogramma spp. thesis, China: Shenyang Agricultural University. PhD Dissertation.
Zhang, J. J., Zhang, X., Zang, L. S., Du, W. M., Hou, Y. Y., Ruan, C. C., et al. (2018). Advantages of diapause in Trichogramma dendrolimi mass production on eggs of the Chinese silkworm. Antheraea pernyi. Pest. Manag. Sci. 74, 959-965. doi: 10.1002/ps.4795

Zhao, L. N., Ma, Y., Yang, X., Iqbal, A., and Zang, L. S. (2019). Identification of Serratia marcescens isolated from Antheraea pernyi eggs and determination of bacterial pathogenicity and transmission pathway. J. Invertebr. Pathol. 169:107297. doi: 10.1016/j.jip.2019.107297

Zhou, J. C., Dong, Q. J., Zhang, T. S., Duan, L. J., Ning, S. F., Liu, Q. Q., et al. (2019a). Effect of wind time on the dispersal capacity of Trichogramma dendrolimi Matsumura (Hymenoptera Trichogrammatidae). J. Asia-Pacific Entomol. 3, 742-749. doi: 10.1016/j.aspen.2019.06.001

Zhou, J. C., Li, Y. Y., Liu, Q. Q., Ning, S. F., Che, W. N., Cong, B., et al. (2019b). Effects of temperature and superparasitism on quality and characteristics of thelytokous Wolbachia-infected Trichogramma dendrolimi Matsumura (Hymenoptera: Trichogrammatidae) during mass rearing. Sci. Rep. 9:18114. doi: 10.1038/s41598-019-54719-5

Zhou, J. C., Liu, Q. Q., Wang, Q. R., Ning, S. F., Che, W. N., and Dong, H. (2020). Optimal clutch size for quality control of bisexual and Wolbachia-infected thelytokous lines of Trichogramma dendrolimi Matsumura (Hymenoptera: Trichogrammatidae) mass reared on eggs of a substitutive host, Antheraea pernyi Guerin-Meneville (Lepidoptera: Saturniidae). Pest Manag. Sci. 76, 26352644. doi: $10.1002 /$ ps.5805

Conflict of Interest: The authors declare that this study received funding from Projects of Guizhou Tobacco Corporation. The funder was not involved in the study design, collection, analysis, interpretation of data, the writing of this article or the decision to submit it for publication.

Publisher's Note: All claims expressed in this article are solely those of the authors and do not necessarily represent those of their affiliated organizations, or those of the publisher, the editors and the reviewers. Any product that may be evaluated in this article, or claim that may be made by its manufacturer, is not guaranteed or endorsed by the publisher.

Copyright (c) 2021 Zhou, Zhao, Liu, Shang, Zhao, Huo, Dong and Zhang. This is an open-access article distributed under the terms of the Creative Commons Attribution License (CC BY). The use, distribution or reproduction in other forums is permitted, provided the original author(s) and the copyright owner(s) are credited and that the original publication in this journal is cited, in accordance with accepted academic practice. No use, distribution or reproduction is permitted which does not comply with these terms. 